\title{
Elucidation of the draft genome sequence of Ideonella azotifigens DSMZ21438 a novel aerobic diazotroph of the Betaproteobacteria isolated from grass rhizosphere soil
}

Richard Allen White III, ${ }^{1,5-6}$ Jeffrey S. Norman, ${ }^{3}$ Emily E. Mclachlan, ${ }^{1}$ Joseph P. Dunham, ${ }^{4}$ Aaron Garoutte, ${ }^{3}$ Maren L. Friesen ${ }^{1-3}$

${ }^{1}$ Department of Plant Pathology, Washington State University, Pullman, WA USA

${ }^{2}$ Department of Crop and Soil Sciences, Washington State University, Pullman, WA USA

${ }^{3}$ Department of Plant Biology, Michigan State University, East Lansing, MI, USA

${ }^{4}$ SeqOnce Biosciences Inc. Pasadena, CA, USA

${ }^{5}$ RAW Molecular Systems (RMS) LLC, Spokane, WA USA

${ }^{6}$ Australian Centre for Astrobiology, University of New South Wales, Sydney, NSW, Australia

Correspondence: Maren L. Friesen, Department of Plant Pathology, Department of Crop and Soil Sciences, Washington State University. Email: m.friesen@wsu.edu

Abstract: Here, we report the draft genome sequence of the type strain of Ideonella azotifigens DSMZ21438 ${ }^{\top}$ (formally $1 \mathrm{a} 22^{\top}=\mathrm{JCM} 15503^{\top}$ ). Ideonella azotifigens DSMZ21438T a novel betaproteobacterial non-symbiotic nitrogen-fixing grass rhizosphere dwelling microbe. The 891,561 paired-end shotgun reads were quality filtered and decontaminated with the ATLAS pipeline, then assembled with Unicycler. The genome size is $6,257,981$ bp, an N50 size of $7,849 \mathrm{bp}$, with a $\mathrm{G}+\mathrm{C}$ content of $66.71 \%$, and with 5,882 predicted protein-coding genes. I. azotifigens DSMZ21438 represents the first member of the genus isolated from rhizosphere soil, providing a framework for further study into non-alphaproteobacterial nitrogen fixation and synthetic biology applications.

Data Set: OSF repo https://osf.io/r9y3g/.

Data Set License: CC-By Attribution 4.0 International

Keywords: Betaproteobacterial diazotroph, free-living nitrogen fixer, synthetic biology 


\section{Summary}

Rhizosphere soils represent one of the most microbially diverse ecosystems on the planet (1-3). Understanding microbes that fix atmospheric nitrogen (i.e., diazotrophs) within the rhizosphere interface is critical for soil health and crop production. Many of these diazotrophic microbes are symbiotic forming nodules within plant roots (e.g., Rhizobium) but some non-symbiotic free-living diazotrophs such as Azotobacter and Ideonella (4-7). As much as $20 \%$ of the global biological nitrogen fixation comes from free-living non-symbiotic diazotrophs, which could act as biofertilizers (4-7).

Ideonella azotifigens DSMZ21438 ${ }^{\top}$ (formally $1 \mathrm{a}^{\top} 2^{\top}=\mathrm{JCM} 15503^{\top}$ ) was isolated from grass rhizosphere from a 30-year old fallow agricultural field (7). Ideonella genus officially proposed by the isolation of Ideonella dechloratans (8). The genus Ideonella recently diverged within Rubrivivax-Roseateles-Leptothrix-Azohydromonas-Aquincola-Ideonella branch within the order Burkholderiales (9). Ideonella has been isolated from diverse environments, including activated sludge (8), recycling plant (10-11), and a freshwater marsh (12).

The resulting de novo assembly was contained on 1219 contigs, with a genome size of $6,257,981 \mathrm{bp}$, an N50 size of $7,849 \mathrm{bp}$, with a $\mathrm{G}+\mathrm{C}$ content of $66.71 \%$. The genome is 95.66\% complete with 1.02\% contamination. Prokka annotation predicts 64 tRNAs, 1 tmRNAs, 1 copy of the 5S-16S-23S operon, 0 CRISPRs, 22 misc RNA (or non-coding RNAs), 1 repeat region, and 5,882 predicted protein-coding genes.

I. azotifigens DSMZ21438 ${ }^{\top}$ represents the first member of the genus isolated from rhizosphere soil (7). Here we provide the draft genome sequence of $I$. azotifigens $\mathrm{DSMZ21438}^{\top}$, which will provide a genomic blueprint of designing diazotrophic synthetic rhizospheres (13). 


\section{Data description}

This Whole Genome Shotgun project and the version described in this paper has been deposited at DDBJ/ENA/GenBank under the accession VIDT00000000. All code can be found at www.github.com/friesenlab/ideonella-azotifigens_DSMZ21438. Fourteen contigs were removed for being $<200 \mathrm{bp}$ for GenBank submission, including the version discussed here. However, all assemblies and annotations are available on the Open Science Framework (OSF) repo for this genome (https://osf.io/r9y3g/).

\section{Methods}

A single colony of $I$. azotifigens DSMZ21438 ${ }^{\top}$ was inoculated in Burk's broth with nitrogen $\left(0.25 \mathrm{~g}^{-1} \mathrm{~L}^{-1} \mathrm{NH}_{4} \mathrm{Cl}\right)$ for DNA extraction in an ambient atmosphere for six days. DNA was extracted and purified using the MasterPure DNA Extraction Kit (Epicentre, Madison WI, USA), following manufacturer's guidelines. DNA was quantified using Qubit Fluorometer 2.0 (Invitrogen, Carlsbad, CA, USA), then quality checked using a Nanodrop-1000 (Thermo Fisher, Waltham, MA, USA). SeqOnce RhinoSeq kit was used for Illumina library preparation following the manufacturer's protocols (https://seqonce.com/rhinoseq/). Michigan State University Research Technology Support Facility (RTSF) sequencing core completed DNA sequencing, library quantification, and sequenced on HiSeq 4000 in 150 bp paired-end read format.

Paired-end shotgun reads were quality filtered, assembled, and decontaminated with the ATLAS pipeline (version 1.0) (14). The 891,561 paired-end (150 bp format) quality controlled were then assembled with Unicycler (version 0.4.7) using default Illumina assembly parameters (15). CheckM (version 1.0.12) was used to estimate completeness and 
contamination (16). Annotation was completed using Prokka (version 1.13.3) with -rfam flag to obtain rRNAs and tmRNAs (17).

\section{Acknowledgments}

We acknowledge support from NSF IOS 1331218 to MLF and NSF DEB 1547024 to MLF and JSN. We acknowledge with special thanks to Dr. Daniel H. Buckley of Cornell for

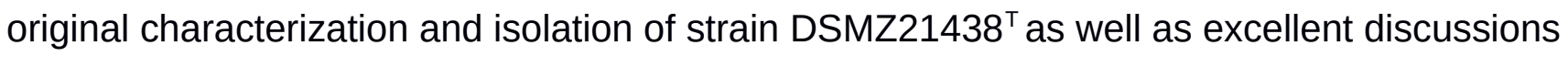
about this unique diazotroph.

\section{References}

1. White III RA, Rivas-Ubach A, Borkum MI, Köberl M, Bilbao A, Colby SM, Hoyt DW, Bingol K, Kim YM, Wendler JP, Hixson KK, Jansson C. The state of rhizospheric science in the era of multi-omics: a practical guide to omics technologies. 2017. Rhizosphere 3(2):212-221.

2. White III RA, Borkum MI, Rivas-Ubach A, Bilbao A, Wendler JP, Colby SM, Köberl M, Jansson C. From data to knowledge: The future of multi-omics data analysis for the rhizosphere. 2017. Rhizosphere 3(2):222-229.

3. Adesemoye AO, Torbert HA, Kloepper JW. Plant growth-promoting rhizobacteria allow reduced application rates of chemical fertilizers. 2009. Microb Ecol. 58:921-929.

4. Werner GD, Cornwell WK, Sprent JI, Kattge J, Kiers ET. A single evolutionary innovation drives the deep evolution of symbiotic $\mathrm{N}_{2}$-fixation in angiosperms. 2014. Nat. Commun., 5:4087. 
5. Tejera, N, Lluch, C, Martínez-Toledo, MV, González-López, J. Isolation and characterization of Azotobacter and Azospirillum strains from the sugarcane rhizosphere. 2005. Plant Soil 270:223-232

6. Tripathy PP, Ayyappan S. Evaluation of Azotobacter and Azospirillum as biofertilizers in aquaculture. 2005. World J Microbiol Biotech 21:1339-1343

7. Noar JD, Buckley DH. Ideonella azotifigens sp. nov., an aerobic diazotroph of the Betaproteobacteria isolated from grass rhizosphere soil, and emended description of the genus Ideonella. 2009. Int J Syst Evol Microbiol. 59(Pt 8):1941-1946.

8. Malmqvist A, Welander T, Moore E, Ternstrom A, Molin G, Stenstrom I. Ideonella dechloratans gen. nov., sp. nov., a new bacterium capable of growing anaerobically with chlorate as an electron-acceptor. 1994. Syst Appl Microbiol 17:58-64.

9. Lechner U, Brodkorb D, Geyer R, Hause G, Härtig C, Auling G, Fayolle-Guichard F, Piveteau P, Müller RH, Rohwerder T. Aquincola tertiaricarbonis gen. nov., sp. nov., a tertiary butyl moiety-degrading bacterium. 2007. Int J Syst Evol Microbiol 57:1295-1303.

10. Tanasupawat S, Takehana T, Yoshida S, Hiraga K, Oda K. Ideonella sakaiensis sp. nov., isolated from a microbial consortium that degrades poly(ethylene terephthalate). 2016. Int J Syst Evol Microbiol. 66(8):2813-2818.

11. Yoshida S, Hiraga K, Takehana T, Taniguchi I, Yamaji H, Maeda Y, Toyohara K, Miyamoto K, Kimura Y, Oda K. A bacterium that degrades and assimilates poly(ethylene 
terephthalate). 2016. Science. 3, 51(6278):1196-1199.

12. Sheu SY, Chen ZH, Young CC, Chen WM. Ideonella paludis sp. nov., isolated from a marsh. 2016. Int J Syst Evol Microbiol. 66(2):1052-1057.

13. Ahkami AH, White III RA, Pubudu P Handakumbura PP, Jansson C. 2017. Rhizosphere engineering: Enhancing sustainable plant ecosystem productivity. Rhizosphere 3(2):233-243

14. White III RA, Brown J, Colby S, Overall CC, Lee J, Zucker J, Glaesemann KR, Jansson C, Jansson JK. ATLAS (Automatic Tool for Local Assembly Structures) - a comprehensive infrastructure for assembly, annotation, and genomic binning of metagenomic and metatranscriptomic data. 2017. PeerJ Preprints 5: e2843v1.

15. Wick RR, Judd LM, Gorrie CL, Holt KE. Unicycler: resolving bacterial genome assemblies from short and long sequencing reads. 2017. PLoS Comput Biol., 13:e1005595.

16. Parks DH, Imelfort M, Skennerton CT, Hugenholtz P, Tyson GW. CheckM: assessing the quality of microbial genomes recovered from isolates, single cells, and metagenomes. 2015. Genome Res., 25(7):1043-55.

17. Seemann T. Prokka: rapid prokaryotic genome annotation. 2014. Bioinformatics. 30(14):2068-9. 